\title{
Contamination of soils with organochlorine pesticides in urban parks in Beijing, China
}

\author{
Xing-hong Li ${ }^{\text {a }}$, Wei Wang ${ }^{\mathrm{b}}$, Juan Wang ${ }^{\mathrm{c}}$, Xue-li Cao ${ }^{\mathrm{c}}$, Xiao-fei Wang ${ }^{\mathrm{a}}$, Jian-chang Liu ${ }^{\mathrm{a}}$, \\ Xiu-fen Liu ${ }^{a}$, Xiao-bai $\mathrm{Xu}^{\mathrm{a}, *}$, Xiang-ning Jiang ${ }^{\mathrm{b}}$ \\ ${ }^{a}$ State Key Laboratory of Environmental Chemistry and Ecotoxicology, Research Center of Eco-Environment Sciences, \\ Chinese Academy of Sciences, P.O. Box 2871, Beijing 100085, China \\ b Beijing Forestry University, Beijing 100084, China \\ ${ }^{\mathrm{c}}$ Beijing Technology and Business University, Beijing 100037, China
}

Received 1 March 2007; received in revised form 17 July 2007; accepted 20 July 2007

Available online 14 September 2007

\begin{abstract}
Urban parks are an integral component of healthy urban living. Since they are frequently visited, an understanding of the environmental quality of these urban facilities is crucial. Here, a study was conducted on the contamination of soils in the parks of Beijing. Organochlorine pesticides (OCPs), which have the potential to cause endocrine disturbances, were considered study objectives. Hexachlorocyclohexanes (HCHs) were found at concentrations of $0.2490-197.0 \mathrm{ng} \mathrm{g}^{-1}$ and dichlorodiphenyltrichloroethanes (DDTs) were found at concentrations of $5.942-1039 \mathrm{ng} \mathrm{g}^{-1}$ in the soils investigated. The preliminary pollution assessment indicated that DDTs have caused high pollution levels in the soils of some parks. Analysis of the sources of contamination showed that HCHs in the soils were derived from an old mixed source of technical HCHs and lindane and that DDTs, which were suspected to have recent application to the soils at some sites, were derived mainly from a mixture of technical DDTs and dicofol containing DDT impurities. An independent sample $t$-test proved that pesticides containing DDTs had been used in large amounts in the soils of parks before $1983(p<0.05)$ and that the levels of DDTs in the soils of parks administered by the Beijing municipal government were significantly higher than the levels in those administered by the district government $(p<0.05)$. However, the main difference in this situation needs to be further studied. This study suggested that open spaces like urban parks were not as sound as was expected and that there was potential for exposure of visitors/ workers in the parks to organochlorine pesticides.
\end{abstract}

(C) 2007 Elsevier Ltd. All rights reserved.

Keywords: DDTs; HCHs; Pollution; POPs

\section{Introduction}

Numerous studies have indicated that toxic trace pollutants might reach concentrations of concern to human health in urban environments (Evans et al., 1992; Mielke et al., 1999; De Kimple and Morel, 2000; Chen et al., 2005; Li et al., 2006; Tulve et al., 2006). In contrast to agricultural soils, urban soils might have a direct influence on public health since pollutants in the soils can easily be

\footnotetext{
* Corresponding author. Tel.: +8610 62919177; fax: +86 1062849348. E-mail address: xuxb@rcees.ac.cn (X.-b. Xu).
}

transferred into humans via ingestion, inhalation, or dermal routes, etc. (De Miguel et al., 1997; Mielke et al., 1999; Madrid et al., 2002; Chen et al., 2005). Urban parks are locations that provide opportunities for a wide range of leisure, sporting and recreational activities, which are valuable for the economic health of our cities and the quality of life of the citizens (Costanza et al., 1997; Salazar et al., 2007). In light of the fact that urban parks perform important environmental and recreational functions for urban life (Tyrväinen et al., 2005), an understanding of the environmental quality of these urban facilities is crucial (Wong et al., 2006). 
Beijing, the capital of China, is the main economic, cultural and political center. As one of the oldest and most densely populated cities in the world, it has over 1000 years of history and more than 8 million urban residents. Parks in Beijing, such as the Forbidden City and the Summer Palace, are endowed with scenic beauty as well as cultural and historic significance and are generally the journey's end for tourists to Beijing. It was estimated that the number of tourists in Beijing exceeded 90 million in 2005. Due to the recreational opportunities afforded and the attractive views, Beijing parks are also popular leisure sites for residents living nearby. However, a primary questionnaire about the environmental quality of parks showed that chemicals of various sorts were applied at various annual frequencies in all of the parks for the purpose of protecting the vegetation in China. Organochlorine pesticides, such as HCHs and DDTs, have been used in large amounts for several decades. Both pyrethroids and organophosphates are the most commonly used pesticides today. This means that there is potential for exposure to chemicals of visitors to the parks and of people working in the parks. It had previously been proved that soils in approximately one-half of the parks investigated in Beijing were seriously polluted with heavy metals (Chen et al., 2005). Nevertheless, little research on soil contamination in urban parks has ever been conducted, and the exposure of humans to chemicals in urban parks has not been well characterized. Pesticides, especially those with environmental persistence like $\mathrm{HCHs}$ and DDTs, easily accumulate in the soil, eventually resulting in human exposure to them directly or indirectly. The present study was conducted as a preliminary survey of soil sanitation in order to evaluate the potential risks to human health and eco-environmental safety in the environment of urban. The approach of the study was to provide information on the extent of contamination by HCHs and DDTs in the soils of Beijing's parks, to determine their spatial distribution, to identify the possible sources of pollution and to explore factors possibly affecting contamination in order to prevent further environmental deterioration in these urban leisure facilities.

\section{Materials and methods}

\subsection{Study area and sample collection}

Beijing is one of the biggest cities in northern China. The city occupies an area of $16807 \mathrm{~km}^{2}$, with $750 \mathrm{~km}^{2}$ classified as urban areas. The climate is dominated by temperate semi-wet monsoons, with daily average temperatures ranging from 10 to $27^{\circ} \mathrm{C}$. Brown soil is the main representative soil type in Beijing. The hypsography of Beijing is higher in the northwest direction than in the southeast direction so that the wind blows and the river flows from the northwest to the southeast area. Twenty-five urban parks, acknowledged as famous scenic sites in Beijing that frequently welcome a large number of visitors, were selected as the study areas. Soil samples from the parks of seven major districts (Xicheng, Dongcheng, Xuanwu, Chongwen, Haidian, Chaoyang and Fengtai districts) were sampled (Fig. 1). Because there was little anthropogenic activity there, soil samples from the Yunmeng Mountain Park (YMS, Huairou district), a national forest park, were also collected in order to understand the effect of anthropogenic activities on the environmental quality of parks.

Based on the areas of the parks, surface soil samples $(0-5 \mathrm{~cm})$ were collected. Each of the composite soil samples

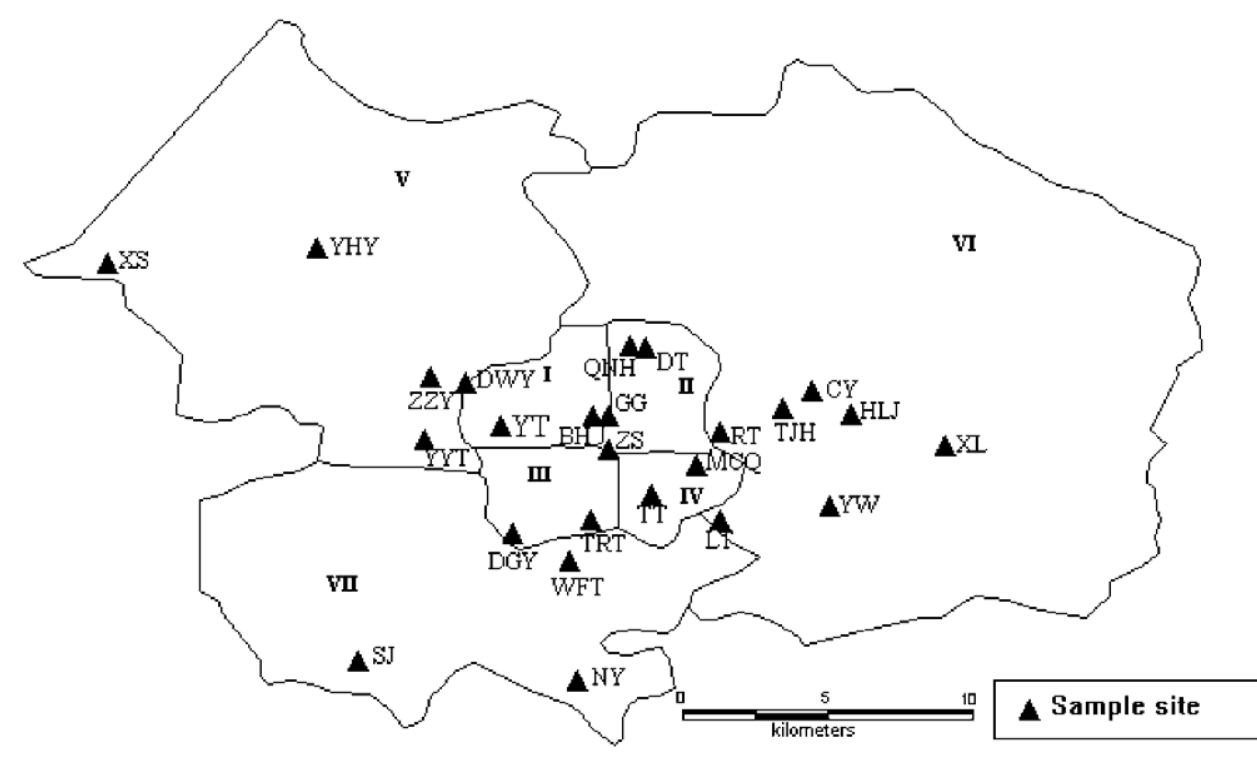

I: Xicheng District; II: Dongcheng District; III: Xuanwu District;

V: Chongwen District; VI: Haidian District; VI: Chaoyang District; VII: Fengtai District

Fig. 1. Sampling sites in the parks of Beijing. 
was made of 14-30 sub-samples in every park, obtained using an acid-cleaned stainless steel hand auger. The soil samples were freeze-dried, thoroughly mixed, sieved to 30 mesh, transferred to pre-cleaned amber glass, and maintained at $4{ }^{\circ} \mathrm{C}$ until further processing. The remaining water content in the soil was determined gravimetrically after drying individual composite soil samples in an oven at $105^{\circ} \mathrm{C}$ for $12 \mathrm{~h}$. All of the results were reported as dry weights.

\subsection{Reagents and standards}

Stock solutions of eight organochlorine pesticides including $\alpha-, \quad \beta-, \quad \gamma-, \delta$-HCH, $p, p^{\prime}$-DDT, $p, p^{\prime}$-DDE, $o, p^{\prime}$-DDT and $p, p^{\prime}$-DDD were obtained from the National Research Center for Certified Reference Materials of China at concentrations of $100.0 \mathrm{mg} \mathrm{l}^{-1}$. 2,4,5,6-Tetrachloro- $m$ xylene (TCMX) was purchased from Supelco (Bellefonte, PA, USA) and was used as a surrogate for $\mathrm{HCHs}$ and DDTs. The standards were further diluted with isooctane to prepare working standards. All solvents were of analytical purity (Beijing Chemical Factory, China) and were redistilled in an all-glass system before use. Florisil (60100 mesh) was purchased from Supelco and was activated in a drying oven at $130{ }^{\circ} \mathrm{C}$ for $16 \mathrm{~h}$. Anhydrous sodium sulfate (Beijing Chemical Factory, China) was first washed with hexane, then heated at $600{ }^{\circ} \mathrm{C}$ for $12 \mathrm{~h}$ before use.

\subsection{Extraction and cleanup}

According to a previously published procedure (Ma et al., 2005), $5 \mathrm{~g}$ of soil were ground with anhydrous sodium sulfate into free flowing powder. The sample was ultrasonically extracted in centrifuge tubes with $30 \mathrm{~mL}$ of $1: 1(\mathrm{~V}: \mathrm{V})$ acetone:hexane for $5 \mathrm{~min}$ and then the extract was separated by centrifugation. The process was repeated three times. The solvents were combined and evaporated by rotary evaporator under reduced pressure in a water bath at $35^{\circ} \mathrm{C}$, and then hexane was added as solvent. The concentrated extract was transferred to a chromatography column $(30 \mathrm{~cm} \times 10 \mathrm{~mm}$ I.D. $)$ containing $5 \mathrm{~g}$ activated Florisil and $1 \mathrm{~g}$ of anhydrous sodium sulfate on the top of the column. The Florisil was soaked in hexane and poured into the column, and was then washed with $40 \mathrm{ml}$ hexane. The concentrated extract was transferred to the top of the column and was eluted by organic solvent. The fraction containing OCPs was eluted by $50 \mathrm{ml}$ of hexane-diethyl ether $(90: 10, \mathrm{~V}: \mathrm{V})$. The solvent was evaporated by rotary evaporator and the sample was adjusted to the volume appropriate for GC analysis.

\subsection{Chromatographic analysis}

Quantification of organochlorine pesticides was carried out with an Agilent 6890 gas chromatograph equipped with a micro-cell $63^{\mathrm{Ni}}$ electron capture detector ( $\mu$-ECD). The separation was performed on a fused silica capillary column (DB-5, $30 \mathrm{~m} \times 0.25 \mathrm{~mm}$ I.D., and $0.25 \mu \mathrm{m}$ film thickness). The carrier gas was nitrogen with a flow of $0.7 \mathrm{ml} \mathrm{min}^{-1}$. The injector and detector temperatures were $225^{\circ} \mathrm{C}$ and $310^{\circ} \mathrm{C}$, respectively. The $\mathrm{GC}$ oven temperature was programmed as follows: initial temperature $100{ }^{\circ} \mathrm{C}$ held for $2 \mathrm{~min}$, increased to $160^{\circ} \mathrm{C}$ at a rate of $10^{\circ} \mathrm{C} \mathrm{min}-1$, then increased to $230{ }^{\circ} \mathrm{C}$ at a rate of $4{ }^{\circ} \mathrm{C} \mathrm{min}{ }^{-1}$, followed by a $10{ }^{\circ} \mathrm{C} \mathrm{min}-1$ ascent to $280^{\circ} \mathrm{C}$, which was maintained for $10 \mathrm{~min}$. Samples $(1 \mu \mathrm{l})$ were injected manually in splitless mode. To confirm the results, selected typical samples were checked with a Hewlett-Parkard 6890 GC5973MSD system. The GC-MS parameters were the same as described above except that the carrier gas was helium. The mass spectrometer was operated in electron impact ionization mode with electron energy of $70 \mathrm{eV}$. Target compounds were monitored with selected ion monitoring (SIM) mode.

\subsection{Quality control}

To reduce or eliminate contamination problems, certain techniques were employed for sampling, solvents, glassware, etc. Surface soil was sampled using an acid-cleaned stainless steel hand auger and the soil layer in contact with the auger was discarded, then the rest was packed in clean aluminum foil and deep frozen for storage. All solvents were redistilled in an all-glass system before use and anhydrous sodium sulfate was first washed with hexane, then heated at $600{ }^{\circ} \mathrm{C}$ for $12 \mathrm{~h}$ before use. Glassware was prepared by successive treatments in the following order: washing with acetone and water, soaking in $5 \% \mathrm{~K}_{2} \mathrm{Cr}_{2} \mathrm{O}_{4}$ sulfuric acid solution overnight, washing with water and distilled water in turn, drying at $350-400{ }^{\circ} \mathrm{C}$, then rinsing with acetone and hexane just before use.

For accuracy and precision of analysis, method blanks were run first using the same solvents as for real samples. No contaminants of organochlorine pesticides were found in the method blanks $(n=3)$. The average recovery experiments were done in triplicate by spiking known concentra-

Table 1

Limits of detection (LODs), limits of quantification (LOQs), calibration curves and recoveries from soil samples of the method

\begin{tabular}{lcccccccc}
\hline & $\alpha-\mathrm{HCH}$ & $\beta$-HCH & $\gamma$-HCH & $\delta$-HCH & $p, p^{\prime}$-DDE & $p, p^{\prime}$-DDD & $o, p^{\prime}$-DDT & $p, p^{\prime}$-DDT \\
\hline LODs $\left(\mathrm{ng} \mathrm{kg}^{-1}\right.$ ) & 44.86 & 75.51 & 99.70 & 114.52 & 97.79 & 147.6 & 143.5 \\
LOQs $\left(\mathrm{ng} \mathrm{kg}^{-1}\right.$ ) & 74.76 & 125.8 & 166.1 & 190.8 & 163.0 & 246.0 & 118.1 \\
Calibration curves $\left(r^{2}\right)$ & 0.9991 & 0.9997 & 0.9995 & 0.9990 & 0.9990 & 0.9989 & 0.9973 \\
Recoveries (\%) & 77.47 & 86.43 & 83.19 & 80.88 & 95.61 & 88.65 & 80.10 & 83.56 \\
\hline
\end{tabular}


tions of standards in a matrix blank. The limits of detection (LODs) were taken as three times the response of the signal-to-noise $(\mathrm{S} / \mathrm{N})$ and the limits of quantification (LOQs) were taken as five-fold $\mathrm{S} / \mathrm{N}$. These parameters are given in Table 1. At the same time, before extraction, each of the soil samples was spiked with a known amount of TCMX as a surrogate to compensate for the loss of components. Recoveries of the TCMX surrogate were 72.11-108.3\% (mean $85.05 \%$ ). The recoveries of surrogate were satisfactory and no correlation of analytical data was applied to the samples. The method blank and matrix blank were measured in duplicate with each batch of ten samples.

\subsection{Data analysis}

A global position system (GPS) was employed to precisely record each location of soil sampling. The spatial distribution of the pollutants was determined by Mapinfo Professional 6.5 SCP. Origin 6.1, and Excel was used to prepare column and line graphs. Conventional statistical analyses and $t$-tests were carried out using SPSS 11.5 statistical software.

\section{Results and discussion}

\section{1. $\mathrm{HCHS}$}

All of the samples contained residues of HCHs (Table 2 ). The total $\mathrm{HCH}$ content (equivalent sum of $\alpha_{-}+$ $\beta-+\gamma-+\delta-\mathrm{HCH})$ ranged from 0.2490 to $197.0 \mathrm{ng} \mathrm{g}^{-1}$ with $39.01 \mathrm{ng} \mathrm{g}^{-1}$ as the standard deviation. The highest concentration was found in Temple of Heaven (TT) and the lowest value was found in Qingnianhu Park (QNH). HCH soil concentrations reported elsewhere in the literature are listed in Table 3. In comparison with other areas of China, the median value $\left(1.768 \mathrm{ng} \mathrm{g}^{-1}\right)$ was slightly higher than that in soils from the Guanting Reservoir, which is located in an exturb of Beijing with fewer anthropogenic activities (median: $0.56 \mathrm{ng} \mathrm{g}^{-1}$, Zhang et al., 2005). However, the geometric mean was 2-8 times lower than that in soils from the urban and suburban areas of Beijing determined via a systematic grid sampling method (geometric mean:
$5.7 \mathrm{ng} \mathrm{g}^{-1}$, Li et al., 2006) and that in agricultural soils from greenhouses in suburban areas of Beijing (15.77 \pm $6.0 \mathrm{ng} \mathrm{g}^{-1}$, Ma et al., 2003). It was also obviously much lower than that in rice soil from Jiaxing, a famous agricultural area in China (18.6-55.4 $\mathrm{ng} \mathrm{g}^{-1}$, Zhao et al., 2002) and that in Tianjin, a city adjacent to Beijing with recent production and usage of $\mathrm{HCHs}$ (45.8 $\mathrm{ng} \mathrm{g}^{-1}$, Gong et al., 2004a). In contrast to urban soils from middle developed countries, the levels were much lower than those in Romania $\left(29.2 \pm 27.1 \mathrm{ng} \mathrm{g}^{-1}\right.$, Covaci et al., 2001) and those in the industrial cities of Poland (Krakow: $11 \pm 29 \mathrm{ng} \mathrm{g}^{-1}$; Kotowice: $6 \pm 3 \mathrm{ng} \mathrm{g}^{-1}$; Falandysz et al., 2001). Compared to tropical/subtropical areas where pollutants easily evaporate from the soils due to the high ambient temperatures, the levels were close to those in urban soils from India (ND-3.6 ng g ${ }^{-1}$, Kawano et al., 1992) and Giza, Egypt (ND-16.2 $\mathrm{ng} \mathrm{g}^{-1}$, Kabbany et al., 2000). Considering China as a developing country and Beijing as having a temperate climate, it seems that the contamination of the soils with $\mathrm{HCHs}$ in the parks of Beijing might be considered as slightly or non-polluting by comparison with the above. Furthermore, it could be also seen that the geometric mean of the HCHs $\left(2.129 \mathrm{ng} \mathrm{g}^{-1}\right)$ was close to the level of the HCHs in YMS $\left(1.263 \mathrm{ng} \mathrm{g}^{-1}\right)$ and was in the range of the levels of $\mathrm{HCH}$ in pristine areas of the Tibetan plateau in China (0.18-5.38 $\mathrm{ng} \mathrm{g}^{-1}$; Fu et al., 2001), suggesting that the concentrations of $\mathrm{HCHs}$ in the soils from most parks was nearly in the range of $\mathrm{HCH}$ background values in the soils of China. However, the large value of the relative standard deviation (RSD, 370.3\%) and the high concentrations in some samples showed that some negative factors probably have had some effects on the levels of $\mathrm{HCHs}$ in the soils investigated.

As for the composition patterns, the content of $\beta-\mathrm{HCH}$ isomers in most of the samples was the highest among the four $\mathrm{HCH}$ isomers and accounted for $26.41-95.68 \%$ of the total HCHs. Compared with the fraction of $\beta-\mathrm{HCHs}$ in technical $\mathrm{HCHs}(5-14 \%$, Qiu et al., 2004), the relatively higher percentages of $\beta-\mathrm{HCH}$ in all of the samples means that there was a lack of new $\mathrm{HCH}$ sources in the research areas. Furthermore, because the ratio of $\alpha-/ \gamma-\mathrm{HCH}$ is relatively stable with a value of $4.64-5.83$ for the technical

Table 2

Descriptive statistics of HCHs and DDTs in the soils of Beijing's parks (ng g $\left.{ }^{-1}\right)$

\begin{tabular}{|c|c|c|c|c|c|c|c|}
\hline Compound & Min. $^{a}$ & Max. ${ }^{a}$ & Mean $^{\mathrm{a}}$ & Median $^{\mathrm{a}}$ & Geometric mean $^{\mathrm{a}}$ & Std. dev. ${ }^{\mathrm{a}}$ & C.V. ${ }^{\mathrm{a}}$ \\
\hline$\alpha-\mathrm{HCH}$ & 0.02243 & 3.817 & 0.3640 & 0.1926 & 0.2104 & 0.7315 & 200.9 \\
\hline$\beta-\mathrm{HCH}$ & 0.03775 & 188.1 & 9.421 & 0.9737 & 1.235 & 37.38 & 396.8 \\
\hline$\gamma-\mathrm{HCH}$ & 0.04985 & 3.221 & 0.5327 & 0.2682 & 0.3265 & 0.7036 & 132.1 \\
\hline$\delta$-HCH & 0.05725 & 1.841 & 0.2170 & 0.1256 & 0.1385 & 0.3498 & 161.2 \\
\hline$\sum \mathrm{HCHs}$ & 0.2490 & 197.0 & 10.54 & 1.768 & 2.129 & 39.01 & 370.3 \\
\hline$p, p^{\prime}-\mathrm{DDE}$ & 1.985 & 202.8 & 57.98 & 37.27 & 27.00 & 60.21 & 103.8 \\
\hline$p, p^{\prime}-\mathrm{DDD}$ & 0.07380 & 22.91 & 1.653 & 0.2361 & 0.210 & 4.690 & 283.7 \\
\hline$o, p^{\prime}$-DDT & 0.5857 & 349.4 & 50.27 & 13.03 & 14.75 & 86.01 & 171.1 \\
\hline$p, p^{\prime}$-DDT & 1.334 & 463.9 & 52.11 & 17.26 & 16.91 & 97.00 & 186.1 \\
\hline$\sum \mathrm{DDTs}$ & 5.942 & 1039 & 162.0 & 64.87 & 65.64 & 235.2 & 145.2 \\
\hline
\end{tabular}

${ }^{a}$ Min., max., mean, median, geometric mean, std. dev., were calculated assuming non-detect (ND) measurements were equal to one-half LODs. 
Table 3

Comparison of HCHs and DDTs in soils from other geographic areas $\left(\mathrm{ng} \mathrm{g}^{-1}\right)$

\begin{tabular}{|c|c|c|c|c|}
\hline Area & Land use & $\sum \mathrm{HCHs}$ & $\sum \mathrm{DDTs}$ & Reference \\
\hline Romania & $\begin{array}{l}\text { Rural soil } \\
\text { Urban soil }\end{array}$ & $\begin{array}{l}28.4 \pm 33.7 \\
29.2 \pm 27.1\end{array}$ & $\begin{array}{l}226.9 \pm 157.2 \\
113.1 \pm 151.8\end{array}$ & Covaci et al., 2001 \\
\hline Krakow, Poland & Urban and rural soil & $11 \pm 29$ & $110 \pm 89$ & Falandysz et al., 2001 \\
\hline Katowice, Poland & Urban and rural soil & $6 \pm 3$ & $260 \pm 620$ & \\
\hline Indian & Park soil & ND-3.6 & $3.4-90$ & Kawano et al., 1992 \\
\hline Giza, Egypt & & ND-16.2 & ND & Kabbany et al., 2000 \\
\hline Beijing, China & Urban and suburban soil & $\begin{array}{l}1.36-48.83 \\
5.3 \text { (Geometric) }\end{array}$ & $\begin{array}{l}0.77-2178.56 \\
38.2 \text { (Geometric) }\end{array}$ & Li et al., 2006 \\
\hline Beijing, China & Exurb soil in the Guanting reservoir & $\begin{array}{l}\text { ND-9.0 } \\
0.56 \text { (median) }\end{array}$ & $\begin{array}{l}\text { ND-94.1 } \\
5.11 \text { (median) }\end{array}$ & Zhang et al., 2005 \\
\hline Beijing, China & Greenhouse soil & $15.8 \pm 6.0$ & $64.4 \pm 30.4$ & Ma et al., 2003 \\
\hline Beijing, China & Soil not used with HCHs and DDTs & $130 \pm 150$ & $390 \pm 1300$ & Li et al., 2006 \\
\hline Tianjin, China & Urban and rural soil & 45.8 & $49.6 \pm 126.8$ & Gong et al., 2004a,b \\
\hline Jiaxing,China & Rice soil & $18.6-55.4$ & $28.6-71.8$ & Zhao et al., 2002 \\
\hline Tibet, China & Soil in pristine areas & $0.2-5.4$ & ND-2.83 & Fu et al., 2001 \\
\hline Beijing, China & Scenic soil in exurb (YMS) & 1.263 & 0.6181 & This study \\
\hline Beijing, China & Park soil & $\begin{array}{l}0.2490-197.0 \\
2.129 \text { (Geometric) }\end{array}$ & $\begin{array}{l}5.942-1039 \\
65.64 \text { (Geometric) }\end{array}$ & This study \\
\hline
\end{tabular}

$\mathrm{ND}=$ not detected

$\mathrm{HCH}$ and nearly zero for lindane (Zhang et al., 2004), it could be used to monitor whether the source was from technical HCHs or lindane (Kim et al., 2002). In the present study, the $\alpha-/ \gamma-\mathrm{HCH}$ ratios varied from 0.08844 to 2.054 , indicating the presence of a potential mixed emission source of lindane and technical HCHs. This result was consistent with other reports on $\mathrm{HCH}$ sources in human milk, pine needles and $\mathrm{PM}_{2.5} / \mathrm{PM}_{10}$ from Beijing ( $\mathrm{Yu}$ et al., 2003; $\mathrm{Xu}$ et al., 2004, 2005). The conclusion could be drawn that $\mathrm{HCHs}$ in the soils investigated might originate from a relatively remote source with the mixing of technical $\mathrm{HCHs}$ and lindane.

\subsection{DDTs}

High concentrations of DDTs were detected in the soils (Table 2). The $\sum$ DDTs (equivalent sum of $p, p^{\prime}$-DDE, $p, p^{\prime}$ DDD, $o, p^{\prime}$-DDT and $p, p^{\prime}$-DDT) ranged from 5.942 to $1039 \mathrm{ng} \mathrm{g}^{-1}$ with a standard deviation of $235.2 \mathrm{ng} \mathrm{g}^{-1}$. TT had the highest levels (1039 $\mathrm{ng} \mathrm{g}^{-1}$ ) and Chaoyang Park (CY) had the lowest (5.942 $\mathrm{ng} \mathrm{g}^{-1}$ ). The levels of DDTs in the soils in the research areas are compared with other domestic and international areas in Table 3 . The geometric mean (65.64 $\mathrm{ng} \mathrm{g}^{-1}$ ) of DDTs in Beijing's parks was considerably higher compared with residual levels in pristine areas of the Tibetan plateau in China (ND-2.83 $\mathrm{ng} \mathrm{g}^{-1}$, $\mathrm{Fu}$ et al., 2001) and that in YMS $\left(0.6181 \mathrm{ng} \mathrm{g}^{-1}\right.$, this study). Furthermore, it was higher than that in soils around the Guanting Reservoir located in the exurb of Beijing with fewer anthropogenic activities (median: $5.11 \mathrm{ng} \mathrm{g}^{-1}$, Zhang et al., 2005), and was even higher than that in the soils from the urban and suburban areas of Beijing determined via systematic grid sampling (geometric mean: $38.2 \mathrm{ng} \mathrm{g}^{-1}, \mathrm{Li}$ et al., 2006). In addition, the level was close to that in the agricultural soils from Beijing suburbs (64.44 \pm $30.36 \mathrm{ng} \mathrm{g}^{-1}$; Ma et al., 2003) and obviously was not lower than the levels in soils not exposed to DDTs in Beijing in 1980 (Li et al., 2006). It was especially worth noticing that the levels of DDTs in this study were 4-5 times higher than those in Tianjin (one of the neighboring cities of Beijing, $11.7 \mathrm{ng} \mathrm{g}^{-1}$ as a geometric mean in the whole region, Gong et al., 2004b), where there was known continuous production of DDTs with an annual production of 2500-3500 tons and some recent applications of DDTs ( Hu and Liu, 2003). Similarly, the levels of DDTs in this study were higher than the range found in soils from India (3.4 $90 \mathrm{ng} \mathrm{g}^{-1}$, Kawano et al., 1992), which was suspected to be the biggest producer and consumer of DDTs (Jaga and Dharmani, 2003; Monirith et al., 2003). The level of DDTs was also close to those in urban soils from middle developed countries such as Romania and Poland (Covaci et al., 2001; Falandysz et al., 2001). Considering China as a developing country and keeping in mind the function of the parks, all of the above suggested that DDT contamination might be a serious problem in the soils of Beijing's parks.

As far as the composition characteristics of DDT and its metabolites, $p, p^{\prime}$-DDE and $p, p^{\prime}$-DDT were the major contributing compounds and accounted for 19.52-66.78\% and $8.736-57.00 \%$ of the total DDTs, respectively. Since the levels of parent compound ( $p, p^{\prime}$-DDT) in the natural environment will decrease with time and the major metabolites are expected to be DDE and DDD, the ratio $\left(p, p^{\prime}\right.$ $\mathrm{DDE}+p, p^{\prime}$-DDD) $/ p, p^{\prime}$-DDT may be used as an indicator of the resident time of $p, p^{\prime}$-DDT in the environment (Qiu et al., 2004). A ratio $>1$ is generally expected for aged mixtures in the environment and a ratio $<1$ indicates relatively recent exposure to the parent DDT (Jaga and Dharmani, 2003). In our study, the ratio of $\left(p, p^{\prime}\right.$-DDE $+p, p^{\prime}$-DDD)/ $p, p^{\prime}$-DDT was $>1$ in $76.00 \%$ samples, which meant the contamination by technical DDT occurred in the past in most of the samples. However, a ratio $<1$ in about one-quarter of the samples indicated new applications of DDTs had 
occurred in some areas such as Beihai park (BH), TT and Zhongshan Park (ZS). As it is well-known that dicofol contains about 3-7\% DDTs as impurities, the application of dicofol could also cause the release of DDTs to the environment. Recently, the ratio $o, p^{\prime}$-DDT $/ p, p^{\prime}$-DDT was used to distinguish DDT pollution caused by technical DDT from that by technical dicofol (Qiu et al., 2005). Since $o, p^{\prime}$ DDT is more unstable than $p, p^{\prime}$-DDT in the environment, it was impossible that the ratio $o, p^{\prime}$-DDT $/ p, p^{\prime}$-DDT would be higher for technical DDT, whereas the characteristic of pollution from dicofol was a higher $o, p^{\prime}$-DDT/ $/ p, p^{\prime}$-DDT ratio than that of technical DDT. Generally, $o, p^{\prime}$-DDT/ $p, p^{\prime}$-DDT ranges from 0.2 to 0.3 in technical DDTs and from 1.3 to 9.3 or higher in dicofol (Qiu et al., 2005). In this study, the ratio varied from 0.1606 to 5.480 , with 0.8793 as the median, and was $>0.3$ in $80.00 \%$ samples, which suggested the important contribution of dicofol. This was also supported by the high percentage of $o, p^{\prime}$-DDT (5.304 $59.05 \%$ ) in the total DDTs. This result regarding the source of DDT agreed with previous reports in human milk, pine needles, PM2.5/PM10.0 and Beijing soil, which considered that there were releases of impure dicofol in Beijing ( $\mathrm{Yu}$ et al., 2003; Xu et al., 2004, 2005; Li et al., 2006). Here, it could be concluded that dicofol was probably an important source of DDTs in the soils of Beijing's parks.

\subsection{The characters of HCHs and DDTs concentration differentiation}

The spatial distributions of HCHs and DDTs in the soils are displayed in Figs. 2 and 3, respectively. It can be seen clearly from Fig. 2 that the level of $\sum \mathrm{HCHs}$ in TT (197.0 $\left.\mathrm{ng} \mathrm{g}^{-1}\right)$ was much higher than at the other sites.
Temple of Heaven (TT), is a cultural park with nearly 600 years' history and beautiful scenery. Considering the large crowds of visitors to TT (nearly 5 million in 2004), there should be further study to find the reason why such high levels of $\mathrm{HCHs}$ still exist since the usage of industrial $\mathrm{HCH}$ has been banned for nearly 30 years in China. However, for DDTs, the spatial distribution was different from that of HCHs. The distribution of DDTs (Fig. 3) suggests that the levels of DDTs in some famous parks, such as Temple of Heaven (TT), Forbidden City (GG), Beihai Park (BH) and Zhongshan Park (ZS), were obviously much higher (Fig. 3), and they were similar to the distributions of heavy metals in the soils of Beijing's parks (Chen et al., 2005). The results indicate that there are concerns about soil environmental quality in the famous parks of Beijing due to the coexistence of inorganic and organic contaminants at high concentrations.

Some factors affecting the distribution of pollutants were investigated by independent sample $t$-test. Since the occurrence of exceptional values can have a great effect on the distribution type of the data, we considered data points beyond the extent of $(A \pm 3 s)$ to be exceptional values, where $A$ denotes the average value for each compound and $s$ is the standard deviation. Data exceeding the value $(A \pm 3 s)$ only were found in the raw data set and were replaced by the maximum value of the data set without exceptional values. Then it was found that the data set approached a normal distribution according to the onesample Kolmogorov-Smirnov test. Independent sample $t$ test of DDT levels measured in parks located within the 2nd Ring-Road and outside the 2nd Ring-Road indicated there were significant differences. Though parks located within the 2nd Ring-Road generally have a long history,

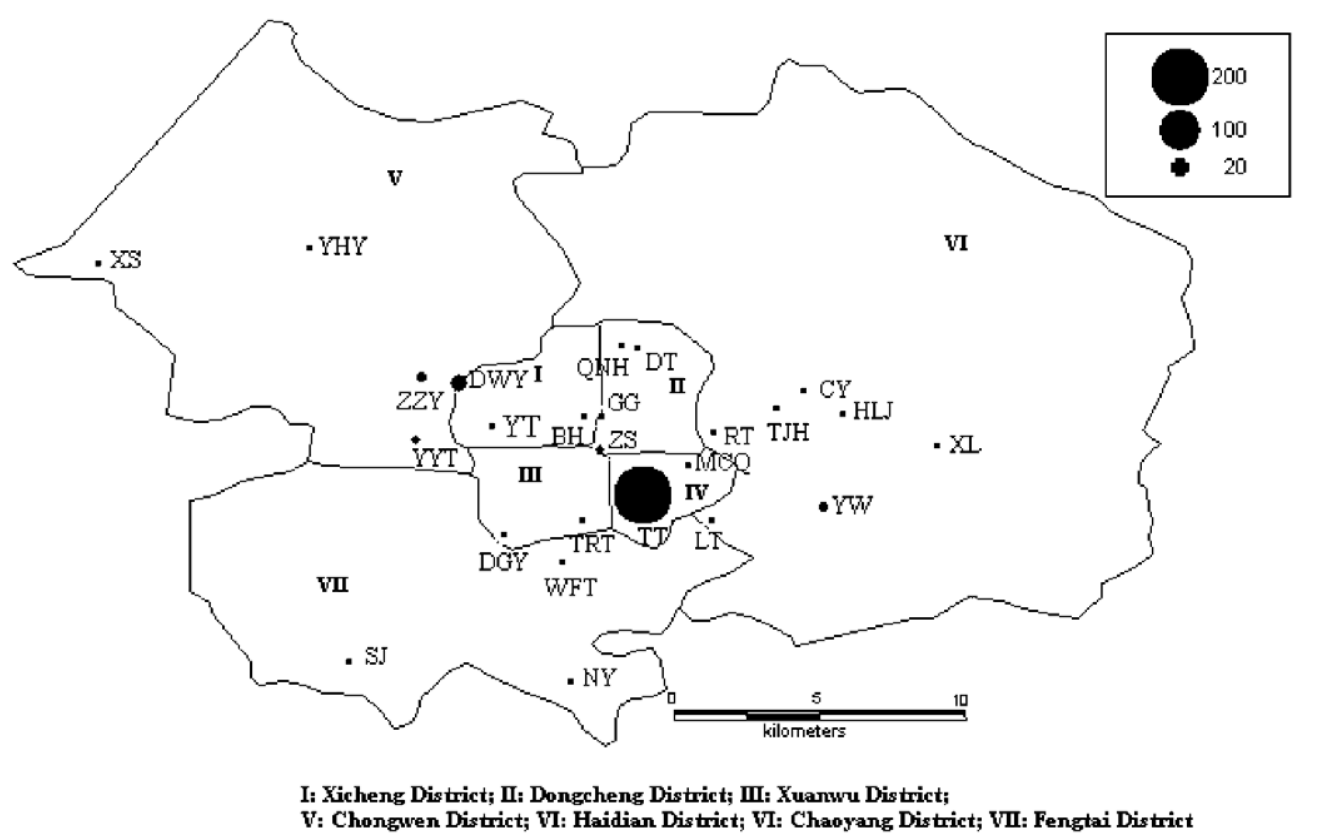

Fig. 2. Spatial distribution of $\sum \mathrm{HCHs}$ in the park soils of Beijing. 


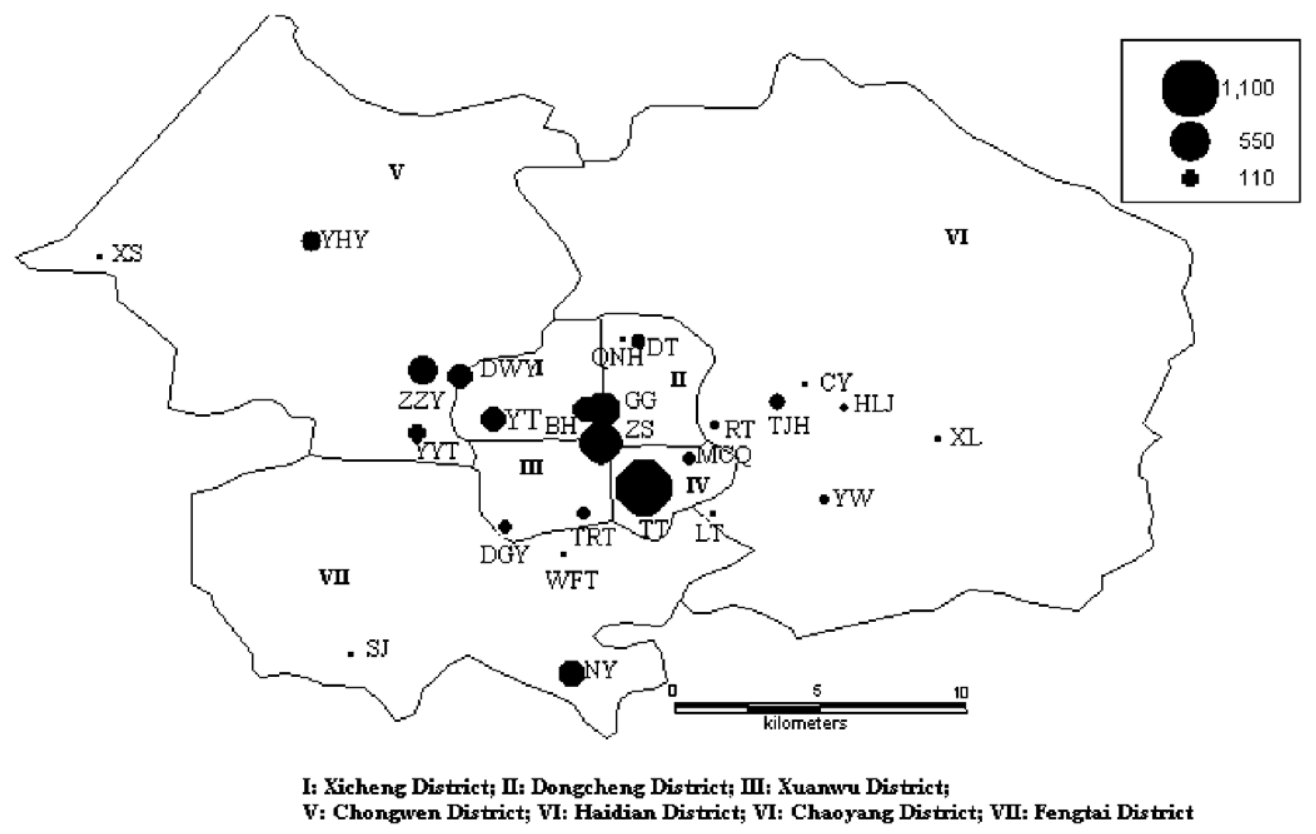

Fig. 3. Spatial distribution of $\sum D D T$ s in the park soils of Beijing.

it seems there is no significant relationship between the level of DDTs and a park's history. However, when the samples collected were classified in terms of the history of the parks being more than 23 years (established before 1983) or less than 23 years (established after 1983), an independent sample $t$-test indicated that the levels of $\mathrm{HCHs}$ showed no significant difference between the two categories. The levels of DDTs in the parks with over 23 years' history were obviously higher than those in the parks of less than 23 years' history. This result probably showed that DDTs as pesticides were applied in large amounts for protecting the vegetation in the parks built 23 years ago and were not applied widely in China after usage was restricted in 1983. In addition, independent sample $t$-test of HCH levels showed an insignificant difference between the parks administered by the Beijing government and the parks administered by the district government, but $t$-test of the DDT levels indicated a significant difference between two. The result was that DDT levels in the parks administered by the Beijing municipal government were significantly higher than in those administered by the district government. However, workers in these parks did not admit to continued DDT usage and POPs scientists in China also denied the probabilities of DDT usage in Beijing's parks after DDT usage was restricted in 1983. It seems that higher DDT levels in the parks administered by the Beijing municipal government were probably related to the fact that most of these parks were built 23 years ago, at which time DDTs were allowed to be used in large amounts to protect the vegetation in the parks in Beijing. However, the main difference in this situation needs to be further studied. In any case, this difference should remind us to pay some attention to the contamination of soils by DDTs in parks managed by Beijing's municipal government.

\subsection{Pollution assessment}

By comparison with the guidelines of the Chinese environmental quality standard for soils (GB15618-1995), the quality of soil was classified as having no pollution, low pollution, middle pollution and high pollution. If the pollution level was below grade I, it was defined as no pollution; if the pollution level was between grade I and grade II, it was defined as low pollution; if the pollution level was between grade II and grade III, it was defined as moderate pollution; and if the pollution level exceeded grade III, it was defined as high pollution. For HCHs, one sample $t$-test shows that the mean in all of the samples collected is significantly lower than the maximum allowable concentration of class I soils in China (50.00 $\mathrm{ng} \mathrm{g}^{-1}$, the guidelines of Chinese environmental quality standard for soil, GB156181995) $(p<0.05)$, suggesting that $\mathrm{HCH}$ pollution in the soils of the parks of Beijing may be categorized as being nonexistent. This may be attributed to the banned usage of industrial $\mathrm{HCHs}$ for nearly 30 years in China. However, $\mathrm{HCH}$ concentrations in TT (Temple of Heaven, $197.0 \mathrm{ng} \mathrm{g}^{-1}$ ) exceeded the standard value of class I soils $\left(50.00 \mathrm{ng} \mathrm{g}^{-1}\right.$, GB15618-1995) about 4 times, and the reason that this level is much higher than the others should be discussed. For DDTs, it was found that the level here was 1-2 orders of magnitude higher than that of HCHs. The concentration of DDTs in $73.00 \%$ samples was between class I (50.00 $\mathrm{ng} \mathrm{g}^{-1}$ ) and class II (500.0 $\left.\mathrm{ng} \mathrm{g}^{-1}\right)$. One sample $t$-test shows that the mean of DDTs is significantly higher than the maximum allowable concentration of class I soils in China (50.00 $\mathrm{ng} \mathrm{g}^{-1}$, the guidelines of Chinese environmental quality standard for soils, GB15618-1995) $(p<0.05)$ and is significantly lower than the maximum allowable concentration of class II soils in China $\left(500.0 \mathrm{ng} \mathrm{g}^{-1}\right.$, 
GB15618-1995) $(p<0.05)$. Therefore, DDT pollution in most samples may be considered as low pollution in this study. However, the level in ZS (618.1 $\mathrm{ng} \mathrm{g}^{-1}$, Zhongshan Park) was between class II and class III (middle pollution) and that in TT (1039 $\left.\mathrm{ng} \mathrm{g}^{-1}\right)$ even exceeded the guideline value for class III (1000 $\mathrm{ng} \mathrm{g}^{-1}$ ) (high pollution). Since DDT together with its metabolites may act as endocrine disruptors, it is necessary to continue to study the DDT levels in these areas. In addition, the factors causing the significant difference in DDT concentrations between parks administered by the Beijing municipal government and those administered by the district government is worth further discussion and study.

\section{Conclusion}

This work revealed soil contamination information regarding $\mathrm{HCHs}$ and DDTs in the park areas of Beijing. The results indicated that $\mathrm{HCH}$ levels might be categorized as no pollution and DDT levels might be categorized as low pollution in most samples. However, there existed high levels of DDTs and HCHs in some parks and there was potential of exposure for park visitors. $\mathrm{HCHs}$ were from the old mixed source of technical $\mathrm{HCHs}$ and lindane in the soils of parks. Though contamination by technical DDTs mainly occurred in the past, the relatively recent use of DDTs was also indicated in one-quarter of samples. Dicofol containing DDT impurities was also probably an important source of contamination of soils besides the technical DDTs. In addition, it seemed that pollution levels of DDTs in the soils of parks could be correlated with the different administration departments and the main difference in this situation needs to be further studied. These findings are important to pursue/control the pollution sources of organochlorine pesticides and enhance the parks' environmental quality. In addition, due to the continuous usage of other chemicals such as pyrethroids and organophosphates in the parks in China, some additional unknown threats from these chemicals might also be present in these regions. Therefore, this study further makes us aware of the fact that the environmental quality in parks is not as sound as it was thought and some attention should be paid to the environmental quality of the parks for the sake of human health and eco-environmental safety.

\section{Acknowledgments}

This work was supported by the National Natural Science Foundation of China and the National Basic Research Program of China (20607026, 2003CB415005).

\section{References}

Chen, T.B., Zheng, Y.M., Lei, M., Huang, Z.C., Wu, H.T., Chen, H., Fan, K.K., Yu, K., Wu, X., Tian, Q.Z., 2005. Assessment of heavy metal pollution in surface soils of urban parks in Beijing, China. Chemosphere 60, 542-551.
Costanza, R., d'Arge, R., de Groot, R., Farber, S., Grasso, M., Hannon, B., Limburg, K., Naeem, S., O’Neill, R.V., Paruelo, J., Raskins, R.G., Sutton, P., Van den Belt, M., 1997. The value of the world's ecosystem services and natural capital. Nature 387, 253-260.

Covaci, A., Hura, C., Schepens, P., 2001. Selected persistent organochlorine pollutants in Romania. Sci. Total. Environ. 280, 143-152.

De Kimple, C.R., Morel, J.F., 2000. Urban soil management: a growing concern. Soil Sci. 165, 31-40.

De Miguel, E., Llamas, J.F., Chacon, E., Berg, T., Larssen, S., Royset, O., Vadset, M., 1997. Origin and patterns of distribution of trace elements in street dust: unleaded petrol and urban lead. Atmos. Environ. 31, 2733-2740.

Evans, E., Ma, M., Kingston, L., Leharne, S., 1992. The speciation pattern of lead in the vicinity of two London schools. Environ. Int. 18, $153-162$.

Falandysz, J., Brudnowska, B., Kawano, M., Wakimoto, T., 2001. Polychlorinated biphenyls and organochlorine pesticides in soils from the southern part of Poland. Arch. Environ. Contam. Toxicol. 40, 173178.

Fu, S., Chu, S.G., Xu, X.B., 2001. Organochlorine pesticide residue in soils from Tibet, China. Bull. Environ. Contam. Toxicol. 66, 171177.

Gong, Z.M., Xu, F.L., Dawson, R., Cao, J., Liu, W.X., Li, B.G., Shen, W.R., Zhang, W.J., Qin, B.P., Sun, R., Tao, S., 2004a. Resi dues of hexachlorocyclohexane isomers and their distribution characteristics in soils in the Tianjin area, China. Arch. Environ. Contam. Toxicol. 46, 432-437.

Gong, Z.M., Tao, S., Xu, F.L., Dawson, R., Liu, W.X., Cui, Y.H., Cao, J., Wang, X.J., Shen, W.R., Zhang, W.J., Qing, B.P., Sun, R., 2004b. Level and distribution of DDT in surface soils from Tianjin, China. Chemosphere 54, 1247-1253.

Hu, J., Liu, J., 2003. Primary assessment report on pesticide POPs in China, Report to GEF.

Jaga, K., Dharmani, C., 2003. Global surveillance of DDT and DDE levels in human tissues. Int. J. Occup. Med. Environ. Health 16, 7-20.

Kabbany, S.E., Rashed, M.M., Zayed, M.A., 2000. Monitoring of the pesticide levels in some water supplies and agricultural land in ElHaram, Giza. J. Hazard. Mater. 72, 11-21.

Kawano, M., Ramesh, A., Thao, V.D., Tatsukawa, R., 1992. Persistent organochlorine insecticide residues in some paddy, upland and urban soils of India. Int. J. Anal. Chem. 48, 163-174.

Kim, S.K., Oh, J.R., Shim, W.J., Lee, D.H., Yim, U.H., Hong, S.H., Shin, Y.B., Lee, D.S., 2002. Geographical distribution and accumulation features of organochlorine residues in bivalves from coastal areas of South Korea. Mar. Pollut. Bull. 45, 268-279.

Li, X.H., Zhu, Y.F., Liu, X.F., Fu, S., Xu, X.B., Cheng, H.X., 2006. Distribution of HCHs and DDTs in Soils from Beijing City, China. Arch. Environ. Contam. Toxicol. 51, 329-336.

Ma, L.L., Chu, S.G., Xu, X.B., 2003. Organic contamination in the greenhouse soils from Beijing suburbs, China. J. Environ. Monit. 5, 786-790.

Ma, L.L., Muir, D., Wang, X.T., Xu, X.B., 2005. Simultaneous analysis of organic pollutants in soils by gas chromatography and gas chromatography mass spectrometry. Int. J. Environ. Anal. Chem. 85, 8998.

Madrid, L., Diaz-Barrientos, E., Madrid, F., 2002. Distribution of heavy metal contents of urban soils in parks of Seville. Chemosphere 49, 1301-1308

Mielke, H.W., Gonzales, C.R., Smith, M.K., Mielke, P.W., 1999. The urban environment and children's health: soils as an integrator of lead, zinc and cadmium in New Orleans, Louisiana, USA. Environ. Res. 81, $117-129$.

Monirith, I., Ueno, D., Takahashi, S., Nakata, H., Sudaryanto, A., Subramanian, A., Karuppiah, S., Ismail, A., Muchtar, M., Zheng, J.S., Richardson, B.J., Prudente, M., Hue, H.D., Tana, T.S., Tkalin, A.V., Tanabe, S., 2003. Asia-Pacific Mussel watch: monitoring contamination of persistent organochlorine compounds in coastal waters of Asian countries. Mar. Pollut. Bull. 46, 281-300. 
Qiu, X., Zhu, T., Li, J., Pan, H., Li, Q., Miao, G., Gong, J., 2004. Organochlorine pesticides in the air around the Taihu Lake, China. Environ. Sci. Technol. 38, 1368-1374.

Qiu, X., Zhu, T., Yao, B., Hu, J., Hu, S., 2005. Contribution of dicofol to the current DDT pollution in China. Environ. Sci. Technol. 39, 43854390.

Salazar, S., del, S., Menéndez, L.G., 2007. Estimating the non-market benefits of an urban park: Does proximity matter? Land Use Policy 24, 296-305.

Tulve, N.S., Jones, P.A., Nishioka, M.G., Fortmann, R.C., Croghan, C.W., Zhou, J.Y., Fraser, A., Cave, C., Friedman, W., 2006. Pesticide Measurements from the first national environmental health survey of child care centers using a multi-residue GC/MS analysis method. Environ. Sci. Technol. 40, 6269-6274.

Tyrväinen, L., Mäkinen, K., Schipperijn, J., 2005. Tools for mapping social values of urban woodlands and other green areas. Landscape and Urban Planning 79, 5-19.

Wong, C.S.C., Li, X.D., Thornton, I., 2006. Urban environment geochemistry of trace metals. Environ. Pollut. 142, 1-16.
Xu, D., Deng, L., Chai, Z., Mao, X., 2004. Organohalogenated compounds in pine needles from Beijing city, China. Chemosphere 57, 1343-1353.

Xu, D., Dan, M., Song, Y., Chai, Z., Zhuang, G., 2005. Concentration characteristics of extractable organohalogens in $\mathrm{PM}_{2.5}$ and $\mathrm{PM}_{10}$ in Beijing, China. Atmos. Environ. 39, 4119-4128.

Yu, H., Zhu, Z., Zhao, X., Zhang, X., Wang, D., 2003. Levels of organochlorine pesticides in Beijing human milk 1998. Bull. Environ. Contam. Toxicol. 70, 193-197.

Zhang, Z.L., Huang, J., Yu, G., Hong, H.S., 2004. Occurrence of PAHs, PCBs and organochlorine pesticides in Tonghui River of Beijing, China. Environ. Pollut. 130, 249-261.

Zhang, H., Lu, Y., Dawson, R.W., Shi, Y., Wang, T., 2005. Classification and ordination of DDT and $\mathrm{HCH}$ in soil samples from the Guanting Reservoir, China. Chemosphere 60, 762-769.

Zhao, Y.W., Chen, K., Ma, X.Y., Yao, K.Y., 2002. A study on the residue of the organochloride pesticides in soils and rice. Zhejiang Pre. Med. $14,1-3$. 